\title{
Roxithromycin inhibits nuclear factor kappaB signaling and endoplasmic reticulum stress in intestinal epithelial cells and ameliorates experimental colitis in mice
}

\author{
Younjeong Choi ${ }^{1}$, Seong-Joon Koh ${ }^{1}$, Hee Sook Lee ${ }^{1}$, Ji Won Kim ${ }^{1}$, Byeong Gwan Kim ${ }^{1}$, \\ Kook Lae Lee ${ }^{1}$ and Joo Sung Kim²
}

${ }^{1}$ Department of Internal Medicine, Seoul National University Boramae Hospital, Seoul National University College of Medicine, Seoul 156707, Korea; ${ }^{2}$ Department of Internal Medicine, Liver Research Institute, Seoul National University College of Medicine,

Seoul 110-744, Korea

Corresponding author: Ji Won Kim. Email: giwkim@hanmail.net

\begin{abstract}
Roxithromycin is known to have anti-inflammatory and immunoregulatory activity. However, little information is available on the effect of roxithromycin in intestinal inflammation. The aim of this study was to investigate the effect of roxithromycin on NF- $\kappa B$ signaling and ER stress in intestinal epithelial cells (IECs) and the effect of roxithromycin on dextran sulfate sodium (DSS)-induced acute colitis in a murine model. HCT116 cells and COLO205 cells were pretreated with roxithromycin and then stimulated with tumor necrosis factor- $\alpha$ (TNF- $\alpha$ ). Interleukin (IL)-8 expression was determined by real-time reverse transcription-polymerase chain reaction. Nuclear factor kappaB (NF- $\kappa \mathrm{B})$ DNA-binding activity and $\mathrm{I}_{\kappa} \mathrm{B}$ phosphorylation/degradation were evaluated by electrophoretic mobility shift assay and Western blot analysis. The molecular markers of endoplasmic reticulum stress, including p-JNK, phosphorylated eukaryotic initiation factor 2 (p-elF2 $\alpha$ ), C/EBP homologous protein (CHOP), and X-box binding protein 1 (XBP1) were evaluated using western blotting and PCR. Mice were given 4\% DSS for five days with or without roxithromycin. Primary IECs were isolated from mice with DSS-induced colitis. Roxithromycin significantly inhibited the upregulated expression of IL-8.

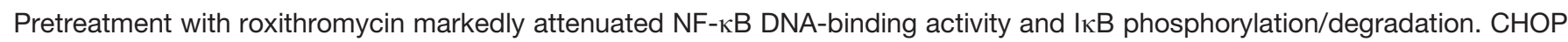
and XBP1 mRNA expression were enhanced in the presence of TNF- $\alpha$, and it was dampened by pretreatment of roxithromycin. c-Jun-N-terminal kinase (JNK) phosphorylation and the level of p-elF2 $\alpha$ were also downregulated by the pretreatment of roxithromycin. Roxithromycin significantly reduced the severity of DSS-induced murine colitis, as assessed by the disease activity index, colon length, and histology. In addition, the DSS-induced phospho-IкB kinase activation was significantly decreased in roxithromycin-pretreated mice. Finally, I $\mathrm{B} B$ degradation was reduced in primary IECs from mice treated with roxithromycin. These results suggest that roxithromycin may have potential usefulness in the treatment of inflammatory bowel disease.
\end{abstract}

Keywords: Roxithromycin, colitis, endoplasmic reticulum stress, nuclear factor-KappaB

Experimental Biology and Medicine 2015; 240: 1664-1671. DOI: 10.1177/1535370215591829

\section{Introduction}

The representative forms of inflammatory bowel disease (IBD), ulcerative colitis (UC), and Crohn's disease (CD) occur in the second and third decades of life and exhibit chronic and relapsing progress. ${ }^{1}$ Patients with IBD present with complications such as perforation, abscess, and toxic megacolon, which result in multiple surgeries and impaired quality of life. ${ }^{2}$ Currently available biologics such as antitumor necrosis factor (TNF)- $\alpha$ agents effectively induce and maintain remission in both $\mathrm{CD}$ and UC patients. In addition, these agents can achieve mucosal healing and improve the quality of life. Nevertheless, the risk-benefit profile of the current biologics remains unclear because of the high cost, long-term safety concerns, and loss of response.,4

The intestinal epithelium is highly important for the immune system. ${ }^{5}$ The intestinal epithelial cell (IEC) lies at the interface between intestinal microbes and the antigenpresenting cells in the lamina propria, ${ }^{5}$ which constitutes a mechanical barrier that protect the host from pathogenic antigen presentation. ${ }^{6}$ In addition, intestinal homeostasis is maintained by the production of various immunoglobulins and inflammatory mediators produced by IECs. $^{7}$ Furthermore, the molecular signal pathway in IECs has a critical role in the pathogenesis of IBD. ${ }^{8}$ The role of the 
nuclear factor-kappaB (NF-кB) has been clearly defined in various reports. ${ }^{9-11}$ It has been suggested that therapeutic agents for IBD such as steroids and 5-aminosalicylic acid exhibit anti-inflammatory effects by blocking NF- $\mathrm{BB}$ signaling in IECs. ${ }^{12}$

Endoplasmic reticulum (ER) stress is defined as the accumulation of misfolded or unfolded proteins within the ER. ${ }^{13}$ When excessive ER stress persists, pro-inflammatory pathways such as the NF- $\kappa \mathrm{B}$ cascade are accelerated or the process of apoptosis is induced. In eukaryotic cells, the unfolded-protein response is initiated to cope with the increased ER stress. ${ }^{13}$ Recently, ER stress in IECs has been reported to play a major role in chronic intestinal inflammation. ${ }^{13}$ Conditional deletion of XBP1 in IECs induces spontaneous development of intestinal inflammation in the small intestine ${ }^{14}$ Genetic abnormalities in the ER stress-related genes such as XBP1 and AGR2 were identified in genomewide association studies. ${ }^{15,16}$ Thus, the modulation of NF$\kappa B$ activity and ER stress in IECs could offer novel targets for therapeutic intervention during the IBD treatment.

Macrolide is known to possess anti-inflammatory and immunomodulatory effects. ${ }^{10}$ However, little is known about the effect of roxithromycin on intestinal inflammation. In this study, we investigated the effect of roxithromycin on NF- $\kappa B$ signaling and ER stress in IECs and the effect of roxithromycin on DSS-induced acute colitis in a murine model.

\section{Materials and methods \\ Cell culture and preparation}

The human intestinal epithelial cell lines, HCT 116 (KCBL; No. 10247) and COLO205 (American Type Culture Collection [ATCC], CCL-222, Rockville, MD, USA) were used between passages 15 and 30. Cells were grown in RPMI 1640 (GIBCO, NY, USA) supplemented with 10\% FBS and antibiotics $(100 \mu \mathrm{g} / \mathrm{mL}$ streptomycin, $100 \mu \mathrm{g} / \mathrm{mL}$ penicillin) as described previously. ${ }^{17}$ Roxithromycin (Sigma, St. Louis, MO, USA) was dissolved in phosphatebuffered saline (PBS). Cells were pretreated with PBS or various concentration of roxithromycin and then were stimulated with TNF- $\alpha$ for the indicated time.

\section{Animals}

All animal procedures were approved by the Institutional Animal Care and Use Committee of Seoul National University Boramae Medical Center. Seven- to eight-weekold male C57BL/6 mice (20-22 g) were purchased from Orient, Korea. The mice were housed under standard conditions of humidity and temperature with a 12-h light/dark cycle. Mice were given ad libitum access to water and standard rodent chow until they reached the desired age (8-9 weeks) and body weight (23-25 g).

\section{Real-time reverse transcription-polymerase chain reaction (RT-PCR)}

RNA preparation and real time RT-PCR were performed as described previously. ${ }^{17,18}$ Total cellular RNA was extracted by treating Trizol (GIBCO) from HCT116 cells.
One microgram of total cellular RNA was reverse transcribed and amplified using the SYBR green PCR Master Mix and ABI prism 7000 sequence detection system (Applied Biosystems, Foster City, CA, USA). We used the following primers specific for human $I L-8, C H O P, X B P 1$, and $\beta$-actin. IL-8, 5'-AAA CCA CCG GAA GGA ACC AT$3^{\prime}$ (sense) and 5'-CCT TCA CAC AGA GCT GCA GAA A-3' (antisense); CHOP, 5'-CAG AAC CAG CAG AGG TCA CA$3^{\prime}$ (sense) and 5'-AGC TGT GCC ACT TTC CTT TC-3' (antisense); XBP1, 5' - AAA CAG AGT AGC AGC TCA GAC TGC-3' (sense) and 5'-TCC TTC TGG GTA GAC CTC TGG GAG-3' (antisense); $\beta$-actin, 5'-ACG GGG TCA CCC ACA CTG TGC CCA TCT A-3' (sense) and 5'-CTA GAA GCA TTG CGG TGG ACG ATG GAG GG-3' (antisense). Gene amplifications were performed in triplicate, and data were normalized to the level of $\beta$-actin expression.

\section{Electrophoretic mobility shift assay (EMSA)}

HCT116 cells were incubated with roxithromycin for $24 \mathrm{~h}$ and then stimulated with TNF- $\alpha$ for $30 \mathrm{~min}$. HCT116 cells were harvested, and the nuclear contents were extracted as described previously. ${ }^{18}$ Nuclear protein was extracted using a commercially available kit (Thermo, Rockford, IL, USA). A Bradford assay (Bio-Rad, Hercules, CA, USA) was used to determine protein concentrations in the extracts. EMSA for NF- $\kappa \mathrm{B}$ was performed using commercially available kits (Promega, Madison, WI). Briefly, $4 \mu \mathrm{g}$ of nuclear extract was mixed with the specified reagents and incubated for $5 \mathrm{~min}$ at room temperature. The mixed extract was incubated at $15^{\circ} \mathrm{C}$ for $30 \mathrm{~min}$ in a thermal cycler with $1 \mu \mathrm{L}$ of probe $\left(5^{\prime}\right.$ AGTTGAGGGGACTTTCCCAGGC-3') corresponding to a

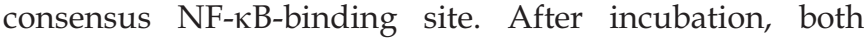
bound and free DNA were resolved on $6 \%$ non-denaturing polyacrylamide gels.

\section{Immunoblot analyses}

HCT116 cells were lysed in $0.5 \mathrm{~mL}$ lysis buffer $(150 \mathrm{mM}$ $\mathrm{NaCl}, 20 \mathrm{mM}$ Tris at pH 7.5, 0.1 Triton X-100, $1 \mathrm{mM}$ PMSF, and $10 \mu \mathrm{g} / \mathrm{mL}$ aprotinin), as described previously. ${ }^{17}$ Protein concentrations were determined using the Bradford assay (Bio-Rad). Twenty micrograms of protein per lane was size fractionated on $10 \%$ polyacrylamide minigel and transferred to a nitrocellulose membrane $(0.1 \mu \mathrm{m}$ pore size). We used Anti-IкB $\alpha$ (Cell Signaling, Beverly, MA, USA), phospho-I $\mathrm{B} \alpha$ (Cell Signaling) as primary antibodies to detect proteins associated with NF- $\mathrm{\kappa B}$ signaling. In addition, we used phospho-JNK, phospho-eIF2 $\alpha$ (Cell Signaling) to evaluate ER stress. Peroxidase-conjugated anti-mouse IgG was used as the secondary antibody. The bound antibodies were detected using the Luminescent Image Analyzer, LAS 4000 (Fuji Film, Tokyo, Japan).

\section{Induction of dextran sulfate sodium (DSS)-induced acute murine colitis and treatment with roxithromycin}

DSS ( $4 \%$, MP biochemical, Irvine, CA, USA) was used to induce acute colitis as described previously. ${ }^{17}$ Mice were divided into three groups as follows: negative control, vehicle-treated group, and roxithromycin-treated group. 
We randomly assigned five mice to each group after they were weighed. Mice assigned to the negative control group received filtered water alone. Both vehicle-treated control and roxithromycin-treated group were administered DSSmixed drinking water for five days. Either vehicle (PBS) or roxithromycin $(10 \mathrm{mg} / \mathrm{kg} /$ day $)$ dissolved in PBS was administered once daily by oral gavage, two days before the DSS administration. We assessed the disease activity index daily by observing body weight loss, stool consistency, and rectal bleeding. Mice were sacrificed on the sixth day after exposure to DSS.

\section{Macroscopic and histopathological analyses}

Macroscopic and histological analyses were performed as described previously. ${ }^{17}$ Postmortem, gross appearance such as bowel edema and the shortening of colon length were evaluated. Both proximal and distal $2 \mathrm{~cm}$ colons were extracted and opened longitudinally for the histopathologic evaluation. The removed colons were fixed in $10 \%$ buffered formalin embedded in paraffin and then stained with Hematoxylin and Eosin (H\&E). A pathologist conducted a blinded quantitative histological evaluation and presented the results using a histologic evaluation scale. ${ }^{19}$ Briefly, the severity of inflammation (amount of inflammation, the extent of injury, and crypt damage) was assessed by a blinded pathologist using a scale from 0 to 3 to quantify the amount of acute inflammation and, the extent of injury, and a scale from 0 to 4 to quantify the amount of crypt damage. The score of each parameter was multiplied by the score for the percentage of tissue involvement.

\section{Immunohistochemical staining}

Immunohistochemical staining was performed as previously described. ${ }^{17,18}$ Briefly, slides were immersed in Tris/ EDTA buffer ( $\mathrm{pH} 9.0$ ), heated in a decloaking chamber for $3 \mathrm{~min}$ at $125^{\circ} \mathrm{C}$, and then cooled for $10-20 \mathrm{~min}$. The sections were incubated for $10 \mathrm{~min}$ after addition of $3 \%$ hydrogen peroxide. The slides were stained with rabbit polyclonal anti-phospho-IкB kinase (IKK)- $\alpha / \beta$ antibody (Cell signaling) in an autoimmunostainer (Autostainer 2D, Lab Vision Co., Fremont, CA, USA) for $1 \mathrm{~h}$ at room temperature. The stained slides were washed with TBS Tween-20 three times and incubated with secondary antibody for $30 \mathrm{~min}$. The slides were reacted with streptavidin for $20 \mathrm{~min}$ and then were incubated with 3,3'-diaminobenzidine tetrahydrochloride for $5 \mathrm{~min}$. The slides were counterstained with Meyer's hematoxylin. Phospho-IKK- $\alpha / \beta$ immunohistochemistry in each slide was assessed on the basis of the reaction intensity, which was evaluated on a scale of 0 to $4+$, as previously described. ${ }^{18}$ Briefly, the overall intensity of phospho-IKK was assessed as follows: 0, no immunoreactivity; $1+$, weak immunoreactivity; $2+$, mild imuunoreactivity; $3+$, moderate immunoreactivity; $4+$, strong immunoreactivity.

\section{Statistical analysis}

Differences between groups were analyzed using analysis of variance with Bonferroni correction or the MannWhitney $\mathrm{U}$ test. $P$ values $<0.05$ were considered statistically significant.

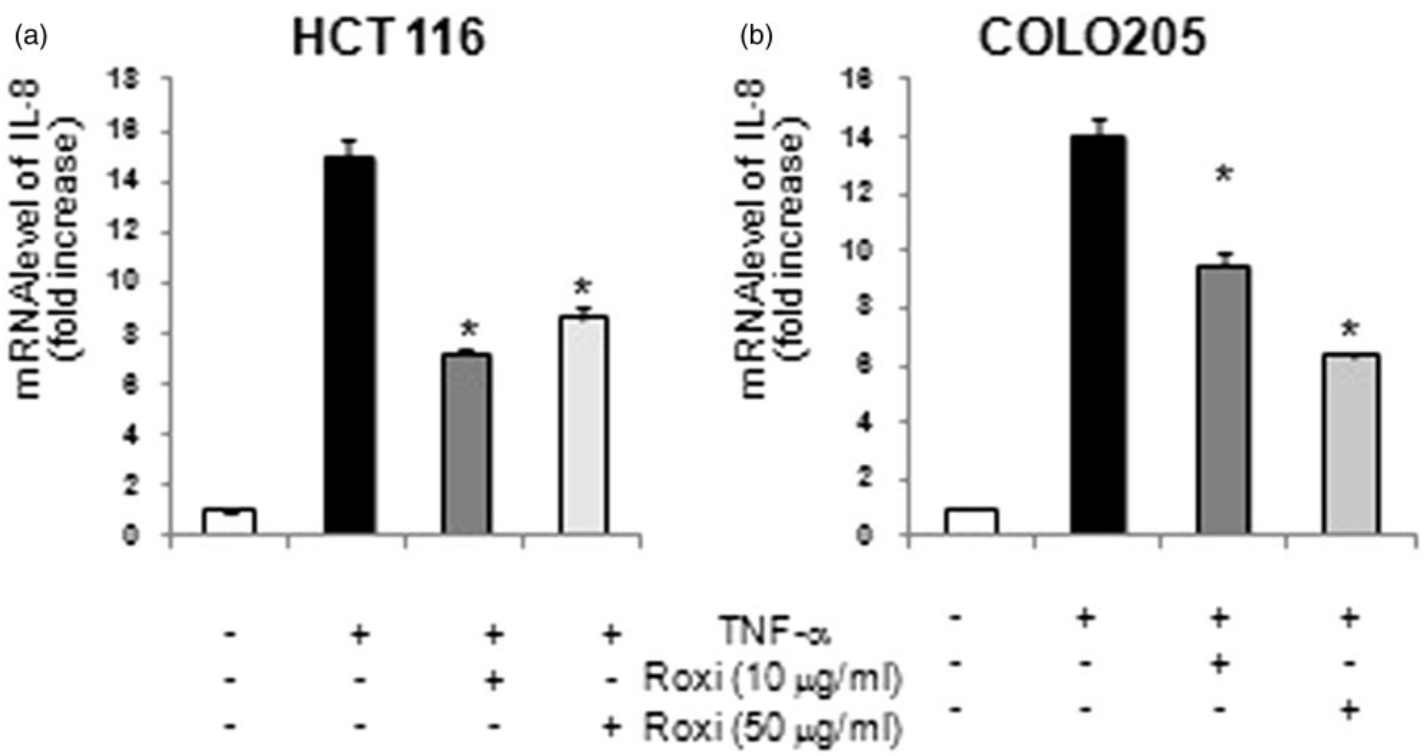

Figure 1 Effects of roxithromycin on interleukin (IL)-8 expression in HCT116 and COLO205 cells stimulated with tumor necrosis factor (TNF)- $\alpha$. (a) HCT166 cells were pretreated with the indicated concentration of roxithromycin for $24 \mathrm{~h}$ and then stimulated with TNF- $\alpha(20 \mathrm{ng} / \mathrm{mL})$ for $8 \mathrm{~h}$. IL- $8 \mathrm{mRNA}$ expression was measured by realtime reverse transcription-polymerase chain reaction (RT-PCR). Levels are normalized to $\beta$-actin. Data are expressed as fold change in messenger RNA (mRNA) transcript levels relative to the unstimulated control (mean $\pm S E M, n=3$ ). (b) COLO205 cells were also pretreated with the indicated concentration of roxithromycin for $24 \mathrm{~h}$ and then stimulated with TNF- $\alpha(20 \mathrm{ng} / \mathrm{mL})$ for $8 \mathrm{~h} .{ }^{*} P<0.05$ compared with TNF- $\alpha$ alone 


\section{Results}

Roxithromycin inhibits TNF- $\alpha$ induced IL-8 expression in intestinal epithelial cells

Because IL- 8 is one of the genes regulated by NF- $\mathrm{KB}$ signaling, we evaluated the effect of roxithromycin on the expression of IL-8 gene. As shown in Figure 1, roxithromycin downregulated the expression of IL-8 in both HCT116 and COL205 cells.

\section{Roxithromycin suppresses NF-кB DNA-binding activity and IKB phosphorylation/degradation in intestinal epithelial cells}

We next examined the effect of roxithromycin on the NF-K DNA-binding activity using EMSA. In HCT116 cells, stimu-

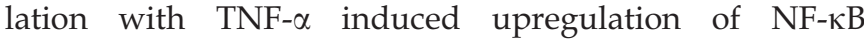
DNA-binding activity. However, pretreatment with roxithromycin reduced TNF- $\alpha$-induced NF- $\kappa \mathrm{B}$ DNA-binding activity (Figure 2(a)). Because NF- $\kappa$ B is released from IкB by IкB phosphorylation, we next examined the effect of roxithromycin on the phosphorylation and degradation of IкB. As shown in Figure 2(b), pretreatment with roxithromycin reduced I $\kappa$ B phosphorylation and reversed its degradation in IECs.

\section{Roxithromycin suppresses TNF- $\alpha$-induced ER stress in IECs}

As the ER chaperone response in IECs has a protective effect on intestinal inflammation, we investigated the role of roxithromycin on the ER stress markers in IECs. Pretreatment with roxithromycin reduced the expression of $\mathrm{CHOP}$ and XBP1 in IECs (Figure 3(a)). In addition, the induction of p-eIF- $2 \alpha$ and p-JNK was reduced by pretreatment with roxithromycin (Figure $3(b)$ ).

\section{Roxithromycin ameliorates DSS-induced acute colitis in mice}

Based on in vitro studies, we believe that roxithromycin has an anti-inflammatory effect in IECs. As IECs play a

(a)
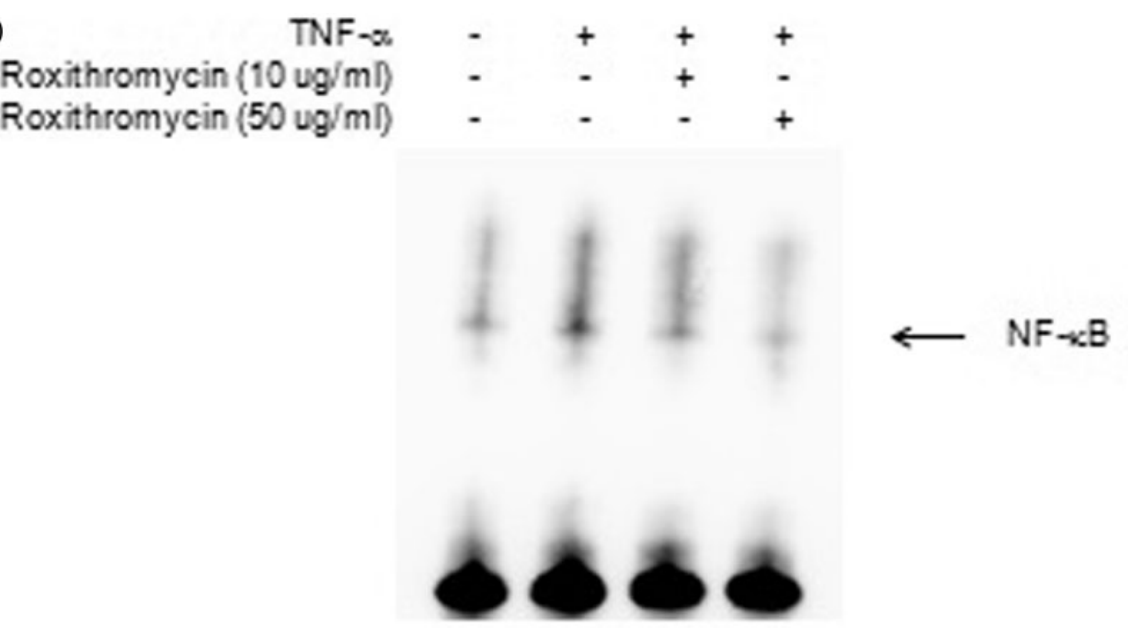

(b)

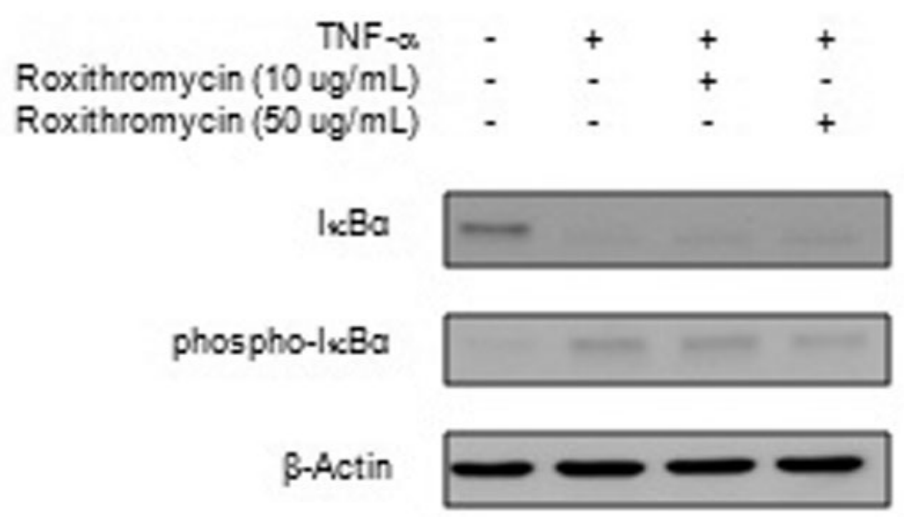

Figure 2 Effects of roxithromycin on nuclear factor-kappaB (NF- $\mathrm{BB}$ ) signaling in TNF- $\alpha$-stimulated HCT116 cells. (a) HCT116 cells were pretreated with the indicated concentration of roxithromycin for $18 \mathrm{~h}$ and then stimulated with TNF- $\alpha(20 \mathrm{ng} / \mathrm{mL})$ for $1 \mathrm{~h}$. NF- $\mathrm{kB}$ DNA-binding activity in the nuclear extracts was assessed by electrophoretic mobility shift assay (EMSA). The data are representative of more than three independent experiments. (b) HCT116 cells were pretreated with the

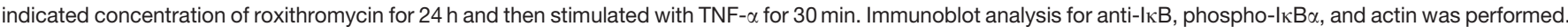
The data are representative of more than three independent experiments. TNF- $\alpha$ : tumor necrosis factor- $\alpha$ 

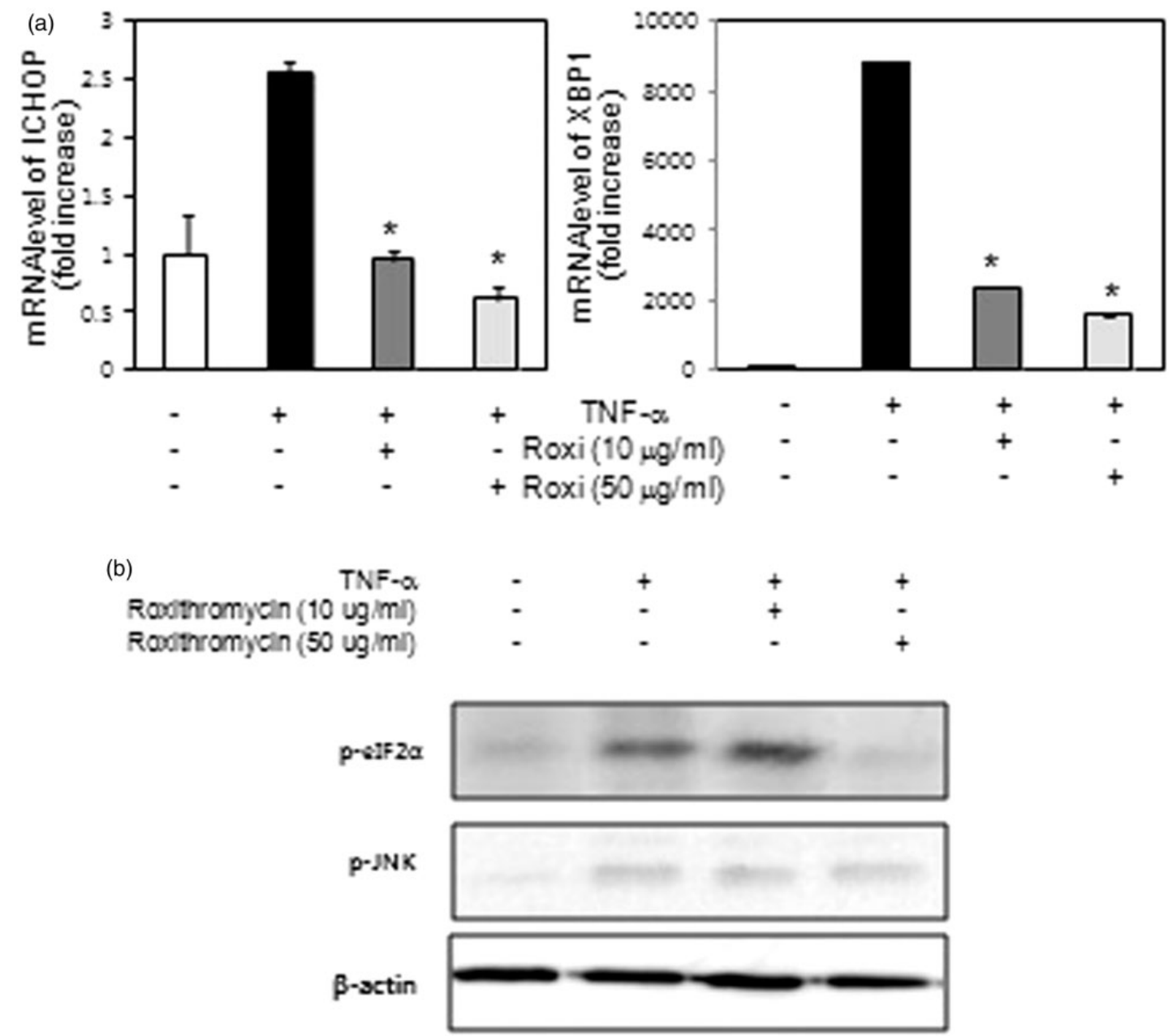

Figure 3 Effects of roxithromycin on endoplasmic reticulum (ER) stress in HCT 116 cells stimulated with TNF- $\alpha$. (a) HCT116 cells were pretreated with the indicated concentration of roxithromycin for $24 \mathrm{~h}$ and then stimulated with TNF- $\alpha(50 \mathrm{ng} / \mathrm{mL})$ for $4 \mathrm{~h}$. CHOP and XBP1 mRNA expression were measured by real-time RT-PCR. The data are representative of more than three independent experiments. (b) HCT116 cells were pretreated with the indicated concentration of roxithromycin for $24 \mathrm{~h}$ and then stimulated with TNF- $\alpha(50 \mathrm{ng} / \mathrm{mL})$ for $60 \mathrm{~min}$. Immunoblot analysis for phosphor-JNK and phospho-elF $2 \alpha$, and $\beta$-actin was performed. The data are representative of more than three independent experiments. TNF- $\alpha$ : tumor necrosis factor- $\alpha$

key role in the regulation of intestinal inflammation, we confirmed these anti-inflammatory effects in a murine model of IBD in vivo. Administration of DSS for five days resulted in substantial body weight loss, diarrhea, and rectal bleeding. In addition, severe edema and shortening of colon length were observed. Administration of roxithromycin attenuated body weight loss and shortening of the colon length. However, there was no significant difference between the PBS and roxithromycin group.

The histopathology was evaluated by a pathologist blinded to the study details. Colitis was induced mainly in distal colons of both PBS and roxithromycin-treated mice. PBS-treated mice showed severe colitis including total destruction of glandular structure, severe infiltration of various inflammatory cells, and crypt damage. However, administration of roxithromycin significantly reduced the mucosal damage and showed regeneration of epithelium. (Figure 4). Histopathologic grading was remarkably reduced in mice treated with roxithromycin $(24.0 \pm 5.6$ versus $9.6 \pm 3.6)$.

\section{Roxithromycin inhibits phospho-IKK immunoreactivity and IKB degradation in IECs of mice with DSS-induced colitis}

Our in vitro study demonstrated that roxithromycin suppressed NF- $\kappa \mathrm{B}$ signaling in IECs. We tried to test this signal in the DSS-induced colitis model. Therefore, we performed immunohistochemistry using an anti-phospho-IKK antibody in a DSS-induced colitis model. As shown in Figure 5(a), DSSinduced colitis was accompanied by increased phospho-IKK immunoreactivity. However, administration of roxithromycin reduced phospho-IKK immunoreactivity in IECs, which significantly reduced the score for immunoreactivity. To confirm this result, we isolated primary IECs from mice with DSS colitis. As shown in Figure 5(b), roxithromycin restored the IкB levels in primary IECs.

\section{Discussion}

In the present study, we investigated the effect of roxithromycin on NF- $\kappa B$ signaling and ER stress in IECs and the 

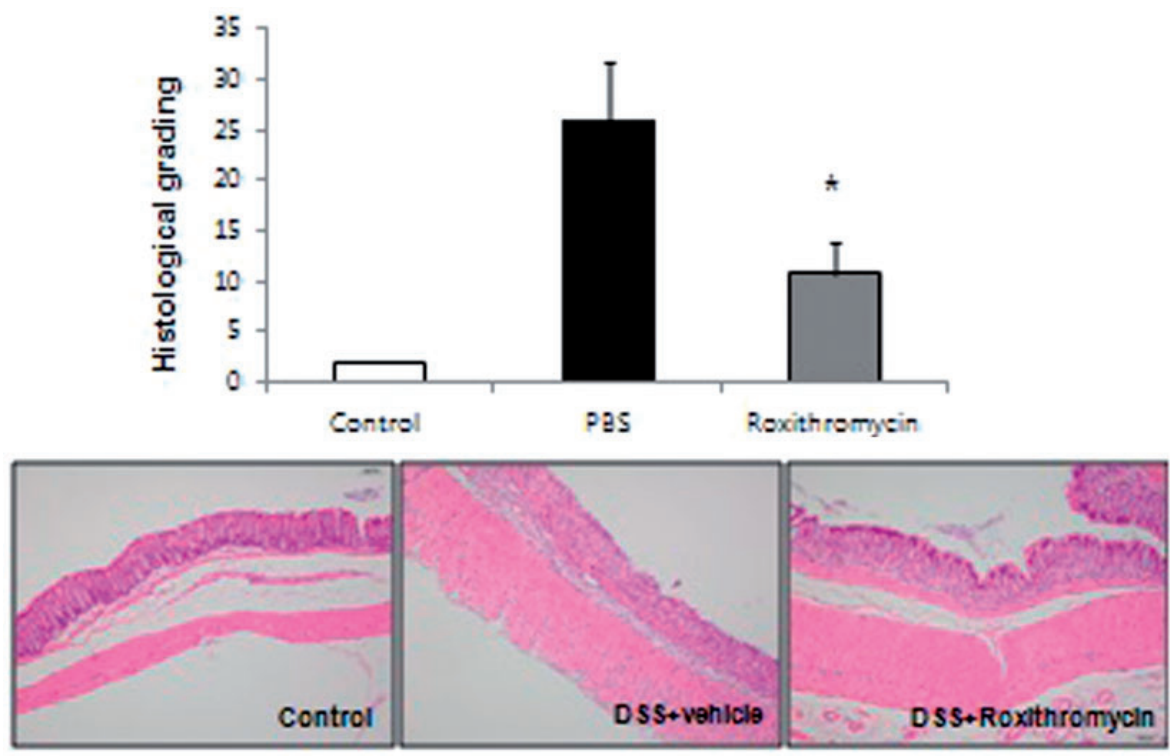

Figure 4 Histological evaluations of colon in the dextran sulfate sodium (DSS)-induced acute murine colitis. Mice were divided into three groups: control, DSS, and vehicle, or DSS and roxithromycin $(10 \mathrm{mg} / \mathrm{kg} /$ day), as described in "Materials and methods" section. The total histological score was derived from the severity and extent of total inflammation and crypt damage (mean \pm SD). DSS-treated mice showed complete destruction of the epithelial architecture with loss of crypts and epithelial integrity, submucosal edema, and intense inflammatory cellular infiltration in all layers. Treatment with roxithromycin attenuated this morphological damage. Results are representative of at least three separate examined sites (Magnification $\times 100)$. PBS: phosphate-buffered saline; roxithromycin: roxithromycin 10 mg/kg/day. ${ }^{\star} P<0.05$ compared with vehicle-treated mice. (A color version of this figure is available in the online journal.)

effect of roxithromycin on DSS-induced acute murine colitis in a mouse model. In the present study, roxithromycin significantly suppressed NF-кB DNA-binding activity and IкB phosphorylation/degradation, resulting in the downregulation of IL-8 mRNA expression. In addition, roxithromycin inhibited ER stress markers including CHOP, XBP1, p-eIF- $2 \alpha$, and p-JNK. Administration of roxithromycin ameliorated DSS-induced acute colitis by inhibiting NF-кB signaling in IECs, which confirmed the anti-inflammatory mechanism of roxithromycin in intestinal inflammation both in vitro and in vivo.

Roxithromycin is a semi-synthetic macrolide antibiotic that has been prescribed for patients with respiratory tract, urinary, and soft tissue infections. Recent data suggest that macrolides may have a beneficial immunomodulatory or neuroprotective effect in neuroimmunological and neurodegenerative diseases including multiple sclerosis, diabetic nephropathy, and amyotrophic lateral sclerosis. ${ }^{10}$ The anti-inflammatory properties were also investigated in atopic dermatitis. ${ }^{20,21}$ Roxithromycin was shown to exert its anti-inflammatory effect by inhibiting the activation of NF- $\mathrm{KB}$ in a mouse model of allergic asthma. ${ }^{22}$ Although a previous study demonstrated that roxithromycin suppressed colitis in IL-10-deficient mice, the basic mechanism remains unclear. Therefore, we explored the effect of roxithromycin in reducing intestinal inflammation. Our results showed that roxithromycin inhibited NF-кB signaling and attenuated ER stress in IECs. In addition, roxithromycin ameliorated DSS-induced acute murine colitis by inhibiting NF- $\kappa \mathrm{B}$ signaling. To the best of our knowledge, this is the first study to elucidate the basic mechanism regarding roxithromycin-induced attenuation of intestinal inflammation.
Our data showed that roxithromycin inhibits NF-кB signaling in IECs. This result was confirmed in DSS-induced colitis model by isolating primary IECs. Taken together, these results suggest that the anti-inflammatory mechanism of roxithromycin involves inhibition of IKK/NF- $\mathrm{KB}$ signaling in the IECs. In addition, the levels of ER stress markers were relieved by treatment with roxithromycin. Previous studies showed that ER stress induces NF-kB activation by the PERK-eIF2 $\alpha$-mediated attenuation of the translocation of IкB. Thus, we believe that the anti-inflammatory mechanism of roxithromycin includes the attenuation of ER stress as well as a direct inhibition of NF- $\kappa B$ signaling in IECs.

NF- $\mathrm{KB}$ signaling in IECs plays a key role in intestinal

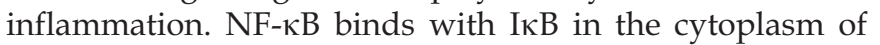
IECs. Following stimulation, such as with TNF- $\alpha$, IкB is phosphorylated by IKK, which leads to NF- $\mathrm{KB}$ translocation into the nucleus. ${ }^{8}$ Our study demonstrated that roxithromy-

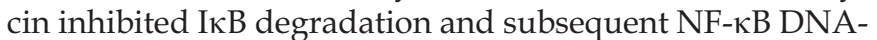
binding activity in IECs. However, a previous study demonstrated that roxithromycin inhibited NF- $\mathrm{\kappa B}$ signaling, independent of the blocking of IкB degradation in epidermal keratinocytes. This result suggests that

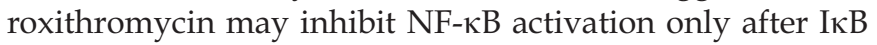
activation. However, it is unclear why this discrepancy occurred. Further studies are needed to elucidate the additional regulating mechanisms underlying NF- $\mathrm{\kappa B}$ signaling in IECs.

Most agents for treating IBD in clinical practice were tested in animal models. Unfortunately, only a small percentage of the promising effects translate to bedside efficacy. In our study, roxithromycin ameliorated DSS-induced acute colitis. In addition, a previous study reported that roxithromycin ameliorated established colitis in IL-10 
(a)
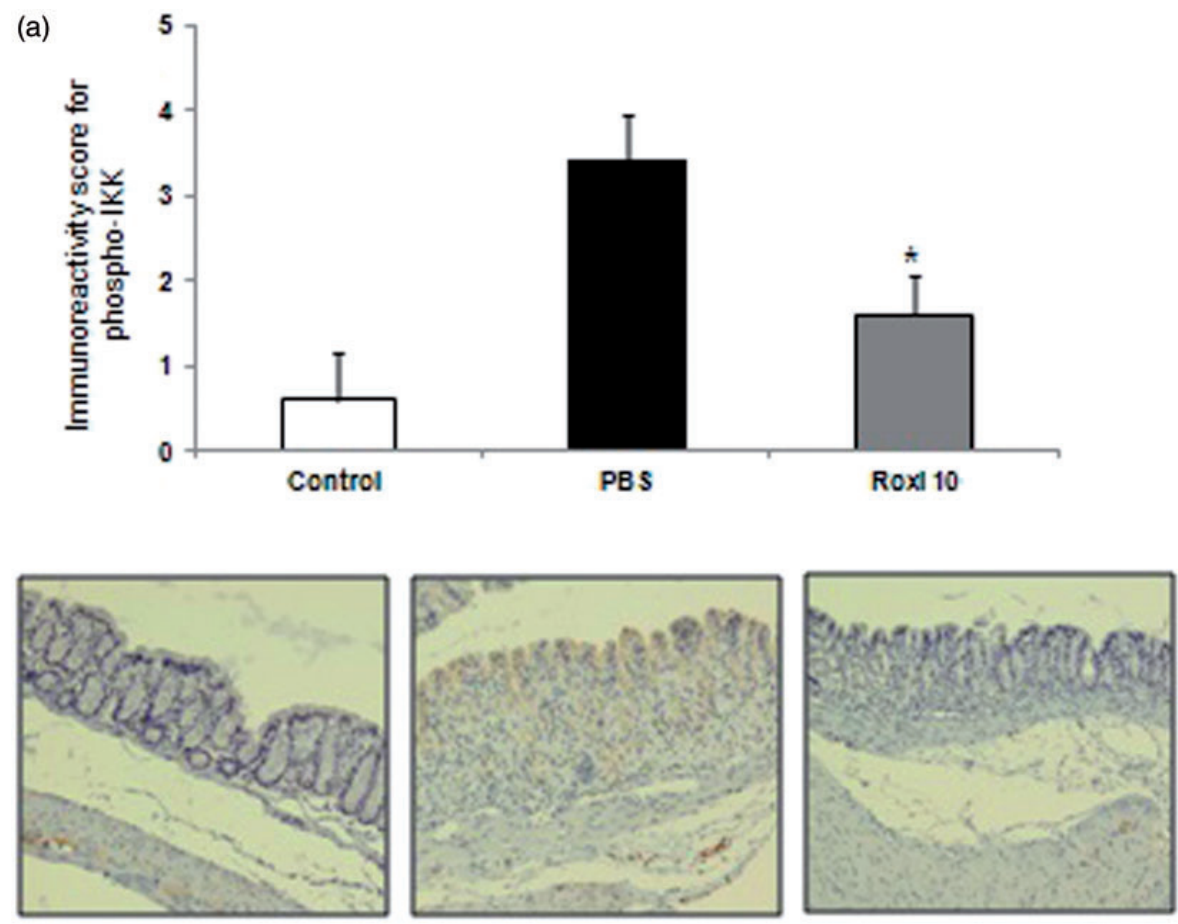

(b)

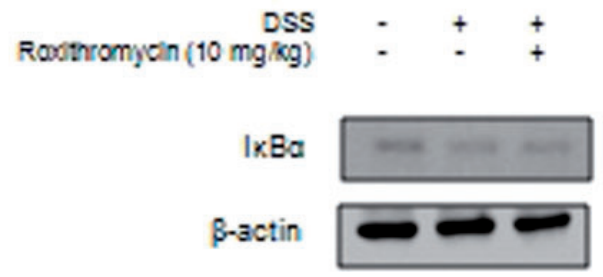

Figure 5 The effect of roxithromycin on NF- $\kappa B$ signaling in mouse intestinal epithelial cells. (a) Immunoreactivity index for phospho-IKK- $\alpha / \beta$ (mean \pm SD) and representative colon samples treated with or without roxithromycin of colonic epithelium in DSS-induced murine colitis. Tissue specimens were stained immunohistochemically with anti-phospho-IKK- $\alpha / \beta$. DSS exposure resulted in a significant increase in the score for phospho-IKK- $\alpha / \beta$ staining compared with control mice. However, administration of roxithromycin ( $10 \mathrm{mg} / \mathrm{kg} / \mathrm{day})$ significantly reduced the degree of phospho-IKK- $\alpha / \beta$ staining in colonic samples (mean $\pm \mathrm{SD}$ ). (b) The effect of roxithromycin on degradation of $\mathrm{I}_{\mathrm{K}} \mathrm{B} \alpha$ in primary intestinal epithelial cells isolated from DSS-induced colitis. The colons were longitudinally cut and washed in PBS. The colons were cut into $0.5 \mathrm{~cm}$ long pieces and incubated at room temperature for $90 \mathrm{~min}$ in a solution of $3 \mathrm{mM}$ EDTA and $0.5 \mathrm{mM}$ DTT with agitation. The resulting supernatant was filtered through a nylon mesh. The cellular suspension was centrifuged, washed, and resuspended in RPMI-1640 with $10 \%$ FBS and antibiotics. DSS: dextran sulfate sodium; PBS: phosphate-buffered saline; roxithromycin: roxithromycin $10 \mathrm{mg} / \mathrm{kg} / \mathrm{day}$. ${ }^{\star} P<0.05$ compared with vehicle-treated mice. (A color version of this figure is available in the online journal.)

knockout $\left({ }^{-1}\right)$ mice, ${ }^{23}$ which suggested that roxithromycin has immense therapeutic potential and that it could be eventually subjected to clinical testing. However, several concerns remain to be resolved. First, it is thought that roxithromycin has better hepatic tolerance because it is slightly metabolized by cytochrome P450. However, a case of acute heptatoxicity after taking roxithromycin has been reported..$^{24}$ In addition, a possible association between roxithromycin and fulminant hepatic failure was reported in a child. ${ }^{25}$ Second, a previous study suggested that the impact of roxithromycin on the intestinal microbiota seems to be weaker than that of other macrolides. ${ }^{26}$ However, the effect of roxithromycin on intestinal microbiota should be elucidated using next-generation sequencing methods. Such studies would help to clarify the usefulness of roxithromycin for the treatment of IBD.

We used a slightly higher dose of roxithromycin, compared with plasma concentration, in the in vitro study. The usual dose in humans results in a maximum plasma concentration of around $10.0 \mu \mathrm{g} / \mathrm{mL} .^{27}$ Therefore, we selected two concentrations for our in vitro studies: a lower concentration within the therapeutic range of serum peak level, and a higher concentration at the possible maximal concentration. A previous study demonstrated that oral administration of roxithromycin at $5 \mathrm{mg} / \mathrm{kg}$ in rata resulted in the maximum plasma concentration of around $1.9 \mu \mathrm{g} / \mathrm{mL}(2.3 \mu \mathrm{M}) .^{28}$ In addition, it has been reported that roxithromycin is excreted from the blood the into intestinal tract unlike the other macrolides. Moreover, a previous study demonstrated that administration of a high dose $(20 \mathrm{mg} / \mathrm{kg}$ per day) of roxithromycin attenuated colitis in IL-10-deficient mice. Therefore, we used a single dose of roxithromycin to evaluate the anti-inflammatory effect in a DSS-induced colitis model.

A limitation of this study is the possibility that roxithromycin can influence the intestinal microbiota. However, our study focused on the anti-inflammatory effect of roxithromycin exerted via the IECs. Finally, it is unclear whether the 
anti-inflammatory effect is specific to a class of macrolides or whether it is only specific to roxithromycin. Further studies are required to determine whether other macrolides have a similar effect.

In conclusion, roxithromycin suppresses the TNF$\alpha$-induced NF- $\mathrm{B}$ pathway, reduces ER stress in IECs, and attenuates acute colitis in mice. Our study supports the utility of roxithromycin as a novel pharmaceutical-grade agent for treating patients with IBD.

\section{AUTHORS' CONTRIBUTIONS}

S-JK and JWK participated in the experimental design; YC and S-JK performed the experiments; YC and S-JK wrote the manuscript; all authors participated in analysis of the data and review of the manuscript; YC and S-JK contributed equally to this work.

\section{ACKNOWLEDGEMENTS}

The authors thank In-Soon Chae for excellent technical assistance. This research was supported by grant from the SNU Boramae Research Fund (03-2014-9) and by Basic Science Research Program through the National Research Foundation of Korea (NRF) funded by the Ministry of Education (grant number NRF-2014R1A1A2057695(S-JK)). This article was presented as a poster at ninth congress of European Crohn's and Colitis Organization, 20-22 February 2014, Copenhagen.

\section{CONFLICT OF INTEREST}

None declared.

\section{REFERENCES}

1. Hanauer SB. Inflammatory bowel disease: epidemiology, pathogenesis, and therapeutic opportunities. Inflamm Bowel Dis 2006;12 Suppl 1:S3-9

2. Loly C, Belaiche J, Louis E. Predictors of severe Crohn's disease. Scand I Gastroenterol 2008;43:948-54

3. Saro C, da la Coba C, Casado MA, Morales JM, Otero B. Resource use in patients with Crohn's disease treated with infliximab. Aliment Pharmacol Ther 2007;26:1313-23

4. Keystone EC. Does anti-tumor necrosis factor-alpha therapy affect risk of serious infection and cancer in patients with rheumatoid arthritis?: a review of longterm data. J Rheumatol 2011;38:1552-62

5. Blumberg RS, Li L, Nusrat A, Parkos CA, Rubin DC, Carrington JL. Recent insights into the integration of the intestinal epithelium within the mucosal environment in health and disease. Mucosal Immunol 2008;1:330-4

6. Chassaing B, Darfeuille-Michaud A. The commensal microbiota and enteropathogens in the pathogenesis of inflammatory bowel diseases. Gastroenterology 2011;140:1720-28

7. Baeuerle PA, Baichwal VR. NF-kappa B as a frequent target for immunosuppressive and anti-inflammatory molecules. Adv Immunol 1997;65:111-37

8. Jobin C, Sartor RB. The I kappa B/NF-kappa B system: a key determinant of mucosal inflammation and protection. Am J Physiol Cell Physiol 2000;278:C451-62

9. Ma TY. Intestinal epithelial barrier dysfunction in Crohn's disease. Proc Soc Exp Biol Med 1997;214:318-27

10. Tauber SC, Nau R. Immunomodulatory properties of antibiotics. Curr Mol Pharmacol 2008;1:68-79

11. Nathens AB, Rotstein OD, Dackiw AP, Marshall JC. Intestinal epithelial cells down-regulate macrophage tumor necrosis factor-alpha secretion: a mechanism for immune homeostasis in the gut-associated lymphoid tissue. Surgery 1995;118:343-50

12. Auphan N, DiDonato JA, Rosette C, Helmberg A, Karin M. Immunosuppression by glucocorticoids: inhibition of NF-kappa B activity through induction of I kappa B synthesis. Science 1995;270:286-90

13. Kaser A, Blumberg RS. Endoplasmic reticulum stress and intestinal inflammation. Mucosal Immunol 2010;3:11-6

14. Calfon M, Zeng H, Urano F, Till JH, Hubbard SR, Harding HP, Clark SG, Ron D. IRE1 couples endoplasmic reticulum load to secretory capacity by processing the XBP-1 mRNA. Nature 2002;415:92-6

15. McGovern DP, Gardet A, Törkvist L, Goyette P, Essers J, Taylor KD, Neale BM, Ong RT, Lagacé C, Li C, Green T, Stevens CR, Beauchamp C, Fleshner PR, Carlson M, D'Amato M, Halfvarson J, Hibberd ML, Lördal M, Padyukov L, Andriulli A, Colombo E, Latiano A, Palmieri O, Bernard EJ, Deslandres C, Hommes DW, de Jong DJ, Stokkers PC, Weersma RK, NIDDK IBD Genetics Consortium, Sharma Y, Silverberg MS, Cho JH, Wu J, Roeder K, Brant SR, Schumm LP, Duerr RH, Dubinsky MC, Glazer NL, Haritunians T, Ippoliti A, Melmed GY, Siscovick DS, Vasiliauskas EA, Targan SR, Annese V, Wijmenga C, Pettersson S, Rotter JI, Xavier RJ, Daly MJ, Rioux JD, Seielstad M. Genome-wide association identifies multiple ulcerative colitis susceptibility loci. Nat Genet 2010;42:332-7

16. Zheng W, Rosenstiel P, Huse K, Sina C, Valentonyte R, Mah N, Zeitlmann L, Grosse J, Ruf N, Nürnberg P, Costello CM, Onnie C, Mathew C, Platzer M, Schreiber S, Hampe J. Evaluation of AGR2 and AGR3 as candidate genes for inflammatory bowel disease. Genes Immunity 2006;7:11-8

17. Koh SJ, Kim JM, Kim IK, Kim N, Jung HC, Song IS, Kim JS. Fluoxetine inhibits NF-kappaB signaling in intestinal epithelial cells and ameliorates experimental colitis and colitis-associated colon cancer in mice. Am J Physiol Gastrointest Liver Physiol 2011;301:G9-19

18. Koh SJ, Kim JM, Kim IK, Ko SH, Kim JS. Anti-inflammatory mechanism of metformin and its effects in intestinal inflammation and colitisassociated colon cancer. J Gastroenterol Hepatol 2014;29:502-10

19. Dieleman LA, Palmen MJ, Akol H, Bloemena E, Peña AS, Meuwissen SG, Van Rees EP. Chronic experimental colitis induced by dextran sulphate sodium (DSS) is characterized by Th1 and Th2 cytokines. Clin Exp Immunol 1998;114:385-91

20. Owczarek W, Paluchowska E. The macrolide antibiotics in treatment of skin diseases. Pol Merkur Lekarski 2008;25:429-31

21. Bornhovd EC, Schuller E, Bieber T, Wollenberg A. Immunosuppressive macrolides and their use in dermatology. Hautarzt 2000;51:646-54

22. Ci X, Chu X, Xu X, Li H, Deng X. Short-term roxithromycin treatment attenuates airway inflammation via MAPK/NF-kappaB activation in a mouse model of allergic asthma. Inflamm Res 2012;61:749-58

23. Tamagawa H, Hiroi T, Mizushima T, Ito T, Matsuda H, Kiyono H. Therapeutic effects of roxithromycin in interleukin-10-deficient colitis. Inflamm Bowel Dis 2007;13:547-56

24. Akcay A, Kanbay M, Sezer S, Ozdemir FN. Acute renal failure and hepatotoxicity associated with roxithromycin. Ann Pharmacother 2004;38:721-2

25. Easton-Carter KL, Hardikar W, Smith AL. Possible roxithromycininduced fulminant hepatic failure in a child. Pharmacotherapy 2001;21:867-70

26. Pecquet $S$, Chachaty E, Tancrède $C$, Andremont A. Effects of roxithromycin on fecal bacteria in human volunteers and resistance to colonization in gnotobiotic mice. Antimicrob Agents Chemother 1991;35:548-52

27. Kees F, Holstege A, Ittner KP, Zimmermann M, Lock G, Schölmerich J, Grobecker H. Pharmacokinetic interaction between proton pump inhibitors and roxithromycin in volunteers. Aliment Pharmacol Ther 2000;14:407-12

28. Arimori K, Miyamoto S, Fukuda K, Nakamura C, Nakano M. Characteristic difference in gastrointestinal excretion of clarithromycin and roxithromycin. Biopharm Drug Dispos 1998;19:433-8

(Received January 28, 2015, Accepted March 11, 2015) 